\title{
High-performance Removal of Anti-inflammatory Using Activated Carbon from Water Treatment Plant Sludge: Fixed-bed and Batch Studies
}

\section{Alaor Valério Filho}

Federal University of Pampa - Bage Campus: Universidade Federal do Pampa

\section{Luana Vaz Tholozan}

Federal University of Pampa - Bage Campus: Universidade Federal do Pampa

Aline Lemos Arim

Federal University of Pampa - Bage Campus: Universidade Federal do Pampa

\section{André Ricardo Felkl de Almeida}

Federal University of Pampa - Bage Campus: Universidade Federal do Pampa

GABRIELA SILVEIRA DA ROSA ( $\nabla$ gabrielarosa@unipampa.edu.br)

Universidade Federal do Pampa https://orcid.org/0000-0002-8831-448X

\section{Research Article}

Keywords: nimesulide, adsorption, hospital effluent, adsorbent, water treatment plant sludge, factorial design

Posted Date: April 5th, 2021

DOI: https://doi.org/10.21203/rs.3.rs-338372/v1

License: (c) (1) This work is licensed under a Creative Commons Attribution 4.0 International License. Read Full License 


\section{High-performance removal of anti-inflammatory using activated carbon from water treatment} plant sludge: fixed-bed and batch studies

Alaor Valério Filho ${ }^{\mathrm{a}}$, Luana Vaz Tholozan ${ }^{\mathrm{b}}$, Aline Lemos Arim ${ }^{\mathrm{b}}$, André Ricardo Felkl de Almeida ${ }^{\mathrm{a}, \mathrm{b}}$, Gabriela Silveira da Rosa ${ }^{a, b}$.

a. Graduate Program in Science and Engineering of Materials, Federal University of Pampa, 1650 Maria Anunciação Gomes Godoy Avenue, Bagé, Rio Grande do Sul 96413-172, Brazil.

b. Chemical Engineering, Federal University of Pampa, 1650 Maria Anunciação Gomes Godoy Avenue, Bagé, Rio Grande do Sul 96413-172, Brazil

Corresponding author:

Gabriela Silveira da Rosa

email: gabrielarosa@unipampa.edu.br

telephone: +55 5332473664

fax: +55 5332473679

\section{Abstract}

Activated carbon from water treatment sludge (WASC) was employed as adsorbent material to remove the anti-inflammatory Nimesulide (NM) from aqueous solutions. NM adsorption was performed in batch and fixed-bed systems, evaluating $\mathrm{pH}$, adsorbent dosage, adsorption kinetics, equilibrium isotherm, continuous adsorption, and simulated effluents. The kinetic data were best fitted to the Elovich model and Intraparticle diffusion reaching the equilibrium at $120 \mathrm{~min}$. Langmuir model presented a better description of the equilibrium data with the maximum adsorption capacity $\left(q_{\max }\right)$ of $274.99 \mathrm{mg} \mathrm{g}^{-1}$ from NM adsorption by WASC. The adsorbent was tested in two simulated hospital effluents and proved to be an excellent adsorbent for removing NM from an aqueous solution with the presence of salts, sugars, and other inorganics. Finally, WASC was applied in fixed-bed NM adsorption obtaining the adsorption capacity of $217.28 \mathrm{mg} \mathrm{g}^{-1}$.

Keywords: nimesulide; adsorption; hospital effluent; adsorbent; water treatment plant sludge; factorial design

\section{Introduction}

The increase of pollutants in the effluents has been considered a major problem for the environment and, consequently, for human life. This situation leads to the reduction of drinking water available (Politano et al. 2017), which is related to global climate change, population growth, industrial and agricultural activity, allied to the improper disposal of contaminants, such as pharmaceuticals in water bodies (Petrie et al. 2015). 
Recent researches have indicated the presence of pharmaceutical compounds in effluents and even drinking water, which classify them as emerging contaminants (Sophia A. and Lima 2018). The main origin of contamination of the environment by pharmaceuticals is through domestic and hospital sewages (SeidMohammadi et al. 2020), since 30-90\% of the ingested is eliminated in urine and feces (Miao et al. 2016). As a consequence of this contamination, the growth of resistant bacteria is causing the inefficiency of usual drugs in the treatment of several diseases (Braschi et al. 2010; Peña-Guzmán et al. 2019).

Regarding emerging pharmaceutical contaminants, the anti-inflammatory NM (nimesulide or 4nitro-2-phenoxyphenyl) has stood out, due to its wide application in the treatment of pain and inflammations in medicine (Lima et al. 2013), which is a result of its great efficacy compared to similar drugs such as ibuprofen, diclofenac, and piroxicam (Singh et al. 2001). The presence of NM in high concentrations was reported by a study carried out in a sewage treatment plant in Greece (Papageorgiou et al. 2016). Seeking a solution to this problem, studies have investigated the removal of NM from effluents (Gonçalves et al. 2016; Reis et al. 2016; Jauris et al. 2017; Wang et al. 2020).

The adsorption process has been widely applied in the removal of emerging contaminants from effluents due to its several advantages (Streit et al. 2020), such as efficiency, flexibility, low cost, simplicity in application, and low energy consumption (Ahmed 2017; Dotto and McKay 2020). Regarding the adsorption of NM in aqueous solutions, it is worth mentioning Reis et al. (2016), Jauris et al. (2017), Saucier et al. (2015), Pauletto et al. (2020) that used adsorbent materials from sewage sludge, graphene, cocoa shell, and commercial activated carbon, respectively.

The development of alternative adsorbents has been considered a great option for the high cost of conventional adsorbents (Puchana-Rosero et al. 2016; Rovani et al. 2016; Ribeiro et al. 2019; Silva et al. 2020). In this sense, water treatment plant sludge (WTS) has been an excellent raw material (Xu et al. 2015; Valério Filho et al. 2020), as the reuse of this residue is a solution for problems related to the high cost of WTS transport, which causes it to be discarded, frequently, in nearby water bodies (Dassanayake et al. 2015; Hidalgo et al. 2017). Moreover, the WTS has important characteristics such as alumina and silica in its composition that can assist in the formation of functional surface groups that have a good interaction with various contaminants present in effluents (Siswoyo et al. 2019).

Thus, the objective of this work was to apply activated carbon from water treatment plant sludge in the adsorption of anti-inflammatory NM. The batch analysis was done by evaluating initial $\mathrm{pH}$, adsorbent dosage, adsorption kinetics, and isotherm. The study also emphasized the treatment of simulated hospital wastewater and the fixed-bed adsorption of NM by WASC, as a proposal for industrial application.

\section{Materials and Methods}

\subsection{Materials and solutions}

NM, with purity $\geq 98 \%$, and all other reagents (analytical grade) were purchased from SigmaAldrich, Brazil. NM was used in this study without further purification. To improve the NM solubilization, the solution was prepared with a solution of ethanol $(20 \% \mathrm{v} / \mathrm{v})$. 
WTS was collected at the water treatment plant in the city of Bagé, Brazil $\left(31^{\circ} 18^{\prime} 22.5^{\prime \prime S}\right.$ $54^{\circ} 07^{\prime} 20.0$ "W). The sample was activated with $\mathrm{ZnCl}_{2}$ and $\mathrm{CaOH}_{2}$ and then pyrolysis was performed at $550^{\circ} \mathrm{C}$ for $30 \mathrm{~min}$. Then acid leaching with $\mathrm{HCl}$ was applied to remove remaining inorganics. The activated carbon produced was named washed activated sludge carbon (WASC) and was characterized using BET, FTIR, DRX, and TGA techniques, the details can be found in a previous paper (Valério Filho et al.).

The reactive groups present on the surface of WASC before and after the NM adsorption were obtained by the Fourier Transform Infrared Spectroscopy (Shimadzu IR Prestige-21, Japan) technique. The spectrum was performed in the range of $500-4500 \mathrm{~cm}^{-1}$ with a resolution of $4 \mathrm{~cm}^{-1}$.

\subsection{Batch studies}

NM solution of $25 \mathrm{~mL}\left(15-800 \mathrm{mg} \mathrm{L}^{-1}\right)$ was added in contact with WASC $\left(0.4-1.6 \mathrm{~g} \mathrm{~L}^{-1}\right)$. The $\mathrm{pH}$ value was investigated in the range of 8 to 11 (adjusted with $\mathrm{NaOH}$ ). A shaker (NOVA ÉTICA, 109-1, Brazil) was used to agitate the mixtures, between 5 and $240 \mathrm{~min}$, at $150 \mathrm{rpm}$. The samples were centrifuged (QUÍMIS, Q222TM216, Brazil) to separate the activated carbon from the NM solution. The concentration of NM was evaluated using standard known concentrations, at the maximum wavelength of $392 \mathrm{~nm}$, in a UV-VIS spectrophotometer (Kazuaki, II-226, China). Equations 1 and 2 were used to determine the adsorption capacity, $\left(q_{e}, \mathrm{mg} \mathrm{g}^{-1}\right)$ and removal efficiency $(E, \%)$, respectively.

$$
\begin{aligned}
& q_{e}=\frac{\left(C_{i}-C_{e}\right) V}{m} \\
& E=\frac{C_{i}-C_{e}}{C_{i}}
\end{aligned}
$$

where $C_{i}$ is the initial NM concentration $\left(\mathrm{mg} \mathrm{L}^{-1}\right) ; C_{e}$, equilibrium $\mathrm{NM}$ concentration $\left(\mathrm{mg} \mathrm{L}^{-1}\right) ; M$, the mass of WASC (g); and $V$, the volume of solution (L).

\subsection{Statistical analysis}

$2^{2}$ Factorial Design (FD) was applied at a 95\% confidence level to understand which factor (adsorbent dosage $\left(A_{d}\left(\mathrm{~g} \mathrm{~L}^{-1}\right)\right)$ and initial $\left.\mathrm{pH}\right)$ would have a major impact on adsorption processes and how these parameters would interact between them. This method was also used to develop a mathematical model to describe the adsorption process. Table 1 shows the independent variables and respective levels used in the experimental design.

Table 1 Independent variables and levels of experimental design.

The FD was carried out with independent variables at 3 levels and it was arbitrated 3 repetitions of the central point to provide an estimate of pure error.

\subsection{Kinetic and isotherm studies}

Four kinetic models were tested to describe experimental data: the pseudo-first order, pseudosecond order, intraparticle diffusion, and Elovich kinetic models were adjusted to experimental data. These models are represented by Equations 3-6, respectively. 


$$
\begin{aligned}
& q_{t}=q_{e}\left(1-e^{-k_{1} t}\right) \\
& q_{t}=\frac{q_{e}^{2}\left(k_{2} t\right)}{\left(1+q_{e} k_{2} t\right)} \\
& q_{t}=k_{i n t} t^{1 / 2}+C \\
& q_{e}=\frac{1}{\alpha} \ln (1+\alpha \beta t)
\end{aligned}
$$

116

where $t$ is the time of contact $(\mathrm{min}) ; q_{t}$ is the amount of $\mathrm{NM}$ adsorbed at time $t\left(\mathrm{mg} \mathrm{g}^{-1}\right) ; k_{l}$ is the pseudofirst order rate constant $\left(\mathrm{min}^{-1}\right) ; k_{2}$ is the pseudo-second order rate constant $\left(\mathrm{g} \mathrm{mg}^{-1} \mathrm{~min}^{-1}\right)$; $k_{i d}$ is the rate constant for intraparticle diffusion $\left(\mathrm{g} \mathrm{mg}^{-1} \mathrm{~min}^{-1 / 2}\right) ; C$ is related to diffusion resistance $\left(\mathrm{mg} \mathrm{g}^{-1}\right) ; \alpha$ is the initial rate of Elovich model $\left(\mathrm{mg} \mathrm{g}^{-1} \mathrm{~min}^{-1}\right)$; and $\beta$ is the Elovich model constants $\left(\mathrm{mg} \mathrm{g}^{-1}\right)$.

Langmuir and Freundlich isotherm models were applied to analyze the equilibrium experimental data. These models are represented in Equations 7 and 8, respectively.

$$
\begin{aligned}
& q_{e}=\frac{q_{\max } K_{L} C_{e}}{1+K_{L} C_{e}} \\
& q_{e}=K_{F} C_{e}^{\frac{1}{n_{F}}}
\end{aligned}
$$

where $q_{\max }$ is the maximum adsorption capacity of the adsorbent ( $\left.\mathrm{mg} \mathrm{g}^{-1}\right), k_{L}$ is the Langmuir equilibrium constant $\left(\mathrm{L} \mathrm{mg}^{-1}\right) ; k_{F}$ is the Freundlich equilibrium constant $\left(\mathrm{mg}^{1-(1 / \mathrm{n})} \mathrm{L}^{1 / \mathrm{n}} / \mathrm{g}\right)$ and $1 / n_{F}$ is the Freundlich exponent.

All model parameters were defined by nonlinear regression, using the quasi-Newton method. The adequacy of the models was analyzed by variance analysis (ANOVA) checked by $F_{\text {value }}>F_{\text {tabled, }}$, were $F_{\text {value }}$ is the regression coefficient. Furthermore, the models were checked by using the Chi-square $\left(\mathrm{X}^{2}\right)$ and average relative error (ARE) according to Equations 9 and 10, respectively.

$$
\begin{aligned}
& A R E=\frac{100}{n n} \sum \frac{q_{\text {exp }}-q_{\text {pred }}}{q_{\text {exp }}} \\
& X^{2}=\sum \frac{\left(q_{\text {exp }}-q_{\text {pred }}\right)^{2}}{n n-N N}
\end{aligned}
$$

where $q_{\text {exp }}$ are the experimental values; $q_{\text {pred }}$ is the value of the model, $n n$ is the experiment number observed, and $N N$ is the number of the parameters in the model.

\subsection{Simulated hospital wastewater}

In this study, two simulated hospital effluents were produced to evaluate NM adsorption by WASC in the middle of sugars, high salt, urea, and other inorganics commonly found in hospital waste effluents (Saucier et al. 2015). Table 2 shows the composition of the simulated effluents.

Table 2 Chemical composition of simulated hospital effluents.

\subsection{Continuous adsorption studies}

The fixed-bed tests were performed on glass columns using $1 \mathrm{~g}$ of WASC. Two columns were used, the internal diameter of column 1 is $5 \mathrm{~mm}$ and the bed height $50.4 \mathrm{~mm}$, column 2 has an internal 
diameter of $9 \mathrm{~mm}$ and $28 \mathrm{~mm}$ of bed height. The NM solution $\left(200 \mathrm{mg} \mathrm{L}^{-1}\right)$ was used to feed the bed with a flow rate of $10 \mathrm{~mL} \mathrm{~min}^{-1}$. Thomas and Yoon-Nelson models were fitted to the experimental fixed-bed data for an estimate of the kinetic parameters, they are represented in Equations 11 and 12, respectively.

$$
\begin{gathered}
C_{t}=\frac{C_{e}}{1+\exp \left(\frac{K_{t h} q_{t h} m}{Q}-k_{t h} C_{e} t\right)} \\
C_{t}=\frac{C_{e}}{1+\exp \left(k_{y n}\left(\tau_{h}-t\right)\right)}
\end{gathered}
$$

were $k_{t h}$ is the Thomas rate constant $\left(\mathrm{mL} \mathrm{mg}^{-1} \mathrm{~min}^{-1}\right) ; q_{\max }$ is the maximum adsorption capacity of Thomas model $\left(\mathrm{mg} \mathrm{g}^{-1}\right) ; Q$ is the flow rate $\left(\mathrm{mL} \mathrm{min}^{-1}\right) ; k_{y n}$ is the Yoon-Nelson rate constant $\left(\mathrm{min}^{-1}\right)$; and $\tau_{h}$ is the time required for $50 \%$ solute breakthrough (min).

\section{Results and Discussion}

Table 3 presents the experimental design of the interaction between adsorbent dosage $\left(A_{d}\right)$ and $\mathrm{pH}$, and the results of adsorption capacity and efficiency of removal of NM by WASC.

Table 3. Experimental results for capacity and efficiency of NM adsorption. Conditions: $C_{i}, 30 \mathrm{mg} \mathrm{L}^{-1}$; contact time, $60 \mathrm{~min}$; temperature, room temperature $\left(25 \pm 2^{\circ} \mathrm{C}\right)$.

The low standard deviation results $\left(0.03-0.91 \mathrm{mg} \mathrm{g}^{-1}\right.$ and $\left.0.10-1.96 \%\right)$ indicate the reproducibility of the experiments. The highest value of $q_{e}$ was $45.06 \mathrm{mg} \mathrm{g}^{-1}$ (run 1), which corresponds to an efficiency of $59.77 \%$, and the highest value for $E$ was $95.31 \%$, which corresponds to an adsorption capacity of 17.83 $\mathrm{mg} \mathrm{g}^{-1}$.

Fig. 1 presents the estimated effects in the adsorption process of NM by WASC for adsorption capacity and efficiency. The reverse elimination process was applied in the statistical analysis of the model, excluding non-significant dependent terms (da Rosa et al. 2019).

Fig. 1 Pareto charts of the estimated effects on adsorption capacity (a) and efficiency (b)

Analyzing the results plotted in pareto charts it can be inferred that the $\mathrm{pH}$ is the most significant effect on the adsorption capacity and efficiency of NM. Fig. 1(a) indicates that all parameters were significant for adsorption capacity $(\mathrm{p}>0.05)$. The $\mathrm{pH}$ was the parameter with the most pronounced negative effect. There is a linear dependence between the $\mathrm{pH}$ and the adsorbent performance, this is, the adsorption capacity decreases with the increase of $\mathrm{pH}$. The interaction between $\mathrm{A}_{d}$ and $\mathrm{pH}$ had a positive effect and $\mathrm{A}_{d}$ had a negative effect.

From the adsorption efficiency presenting in Fig. 1(b), the more pronounced effect was the $\mathrm{pH}$ with the negative effect. The $A_{d}$ parameters had a positive effect and the interaction between $A_{d}$ and $p H$ was not significant $(p \leq 0.05)$. The $A_{d}$ antagonist behavior from adsorption capacity and efficiency can be explained by the high values of $A_{d}$, which promotes an increase in adsorption efficiency. Although it increases the presence of free sites in WASC and, consequently, leads to the decreasing of adsorption capacity. Due to this, the central point $1 \mathrm{~g} \mathrm{~L}^{-1}$ for $\mathrm{A}_{\mathrm{d}}$ was chosen to continue the batch tests. 
The $\mathrm{pH}$ of the solution is an important factor to be observed during pharmaceutical adsorption because affects the surface charge of the adsorbent (Arim et al. 2018). Studies have already reported that in solutions at pH lower than 7 the NM precipitates (Saucier et al. 2015; Jauris et al. 2017). Fig. 1(a-b) and Table 3 indicates that the best $\mathrm{pH}$ condition for a higher $q_{e}$ was at initial $\mathrm{pH} 8$. The higher the $\mathrm{pH}$, the lower the concentration of $\mathrm{H}^{+}$ions. This indicates that the WASC surface must be negative and that interaction between WASC-NM does not occur electrostatically (Saucier et al. 2015). The interaction probably occurs through H bonding and van der Waals forces (Saucier et al. 2015; Jauris et al. 2017).

The kinetic behavior of NM adsorption by WASC and the adjustments of the pseudo-first order, pseudo-second order, Elovich, and intraparticle diffusion mathematical models are presented in Fig. 2.

Fig. 2 Kinetic curves and mathematical model adjustments of pseudo-first order, pseudo-second order, and Elovich models (a) and intraparticle diffusion (b). Conditions: $C_{i}, 30 \mathrm{mg} \mathrm{L}^{-1} ; \mathrm{pH}, 8 ; A_{d}, 1 \mathrm{~g} \mathrm{~L}^{-1}$; temperature, room temperature $\left(25 \pm 2^{\circ} \mathrm{C}\right)$.

It can be observed in Fig. 2(a) that the sorption rate is higher at the beginning of the process because of the greater number of active sites on the surface of the adsorbent (Arim et al. 2019). The experimental data show that most NM was removed around 90 minutes and no significant changes in terms of removal were observed after $120 \mathrm{~min}$.

Fig. 2(b) presenting the limiting rate step for the adsorption process of NM onto WASC, using the intraparticle diffusion model. Three steps can be identified in the kinetic plots. The first step is related to the surface diffusion, with the mass transfer of the NM to the external surface of the WASC particles (Alves et al. 2013). The second step is related to the intraparticle diffusion and the third step indicates the equilibrium phase due to the NM occupation of all the active sites of WASC (Arim et al. 2018).

The kinetic parameter values obtained from the fitting of the kinetic models to experimental data are presented in Table 4.

Table 4 Kinetic parameters of NM anti-inflammatory adsorption in WASC.

All models were checked by the statistical significance through the regression $\mathrm{F}$ test and the values obtained indicated which models presented a good fit. The Elovich and Intraparticle diffusion models describe better the adsorption kinetic as indicated by the highest coefficient of determination, $\mathrm{R}^{2}$, even though the Intraparticle diffusion model shows the lowest values for $X^{2}$ and ARE. The parameters values of intraparticle diffusion obtained from NM adsorption onto WASC were $k_{i n t}=1.94 \mathrm{~g} \mathrm{mg}^{-1} \mathrm{~min}^{-1 / 2}$ and $C=$ $7.93 \mathrm{mg} \mathrm{g}^{-1}$ which represents intraparticle rate constants and boundary layer thickness, respectively (AlRashdi et al. 2012; Arim et al. 2018). The $C$ values different from zero indicate that more mechanisms were involved in NM adsorption (Arim et al. 2018).

The good fit for the Elovich model can indicate the presence of chemisorption in NM removal, not a first-order reaction [30], such behavior is confirmed to the high adjustment for the pseudo-second order model. This means that the NM molecule was dissociated into independent fragments creating radicals and atoms attached to the adsorbent (Dotto and McKay 2020). The parameters $\alpha\left(0.2142 \mathrm{mg} \mathrm{g}^{-1} \mathrm{~min}^{-1}\right)$ and $\beta$ 
(9.89 $\left.\mathrm{mg} \mathrm{g}^{-1}\right)$ of this model represent the initial rate of chemisorption and the number of sites available for NM adsorption, respectively. The Pseudo-first order model has also presented a good fit, which indicates that van der Waals forces and H bonding can occur in the NM adsorption (Saucier et al. 2015; Jauris et al. 2017).

The equilibrium experimental data of NM adsorption onto WASC and the adjustment of the isotherm models are presented in Fig. 3 and their parameters in Table 5.

Fig. 3 Isotherm curve from adsorption of NM on WASC. Conditions: $C_{i}, 15-800 \mathrm{mg} \mathrm{L}^{-1} ; \mathrm{pH}, 8 ; \mathrm{A}_{\mathrm{d}}, 1 \mathrm{~g} \mathrm{~L}^{-}$ ${ }^{1}$; contact time, $180 \mathrm{~min}$; temperature, room temperature $\left(25 \pm 2^{\circ} \mathrm{C}\right)$.

Table 5. Isotherm parameters of NM anti-inflammatory adsorption in WASC

The isotherm curves (Fig. 3) indicate a favorable adsorption process from NM adsorption onto WASC, it occurs when the increase of the adsorption capacity and the increase of adsorbate concentration are proportional (Silva et al. 2020). The good results for NM adsorption can be related to the WASC surface area of $582.0 \mathrm{~m}^{2} \mathrm{~g}^{-1}$. Also, the predominant mesoporous size distribution (3.02 nm) for WASC (Valério Filho et al.) and the extreme distances between the atoms of NM molecule of $0.993 \mathrm{~nm}$ (Saucier et al. 2015) indicate that WASC is capable to adsorb NM anti-inflammatory.

The Langmuir isotherm is the best model for describing the experimental data, considering the highest values of $\mathrm{R}^{2}$ and $\mathrm{F}_{\text {value }}$ and also the lowest values of $\mathrm{X}^{2}$ and ARE. The maximum sorption capacity of NM onto WASC was $274.99 \mathrm{mg} \mathrm{g}^{-1}$, the value is superior to studies that have already investigated the adsorption of NM. The maximum sorption of NM previously reported in the literature was $q_{\max }$ of 14.18 mg. $\mathrm{g}^{-1}$, using a silica aerogel (Caputo et al. 2012); $q_{\max }$ of $26.12 \mathrm{mg} \cdot \mathrm{g}^{-1}$, using a combination of polysiloxanes and sewage sludge (Simões dos Reis et al. 2016); $q_{\max }$ of $66.45 \mathrm{mg} \cdot \mathrm{g}^{-1}$, using activated carbon from sewage sludge (Reis et al. 2016); $q_{\max }$ of $74.81 \mathrm{mg} . \mathrm{g}^{-1}$, using activated carbon from cocoa shell (Saucier et al. 2015); and $q_{\max }$ of $82.4 \mathrm{mg} . \mathrm{g}^{-1}$, using a graphene material (Jauris et al. 2017). Due to the excellent values for maximum adsorption capacity, in Fig. 4 the adsorption of NM by WASC was analyzed in a competitive environment with other inorganics, sugars, and salts. The chemical composition of simulated hospital effluents is showing in Table 2 .

Fig. 4 Adsorption efficiency of NM in hospital effluents treatment with WASC. Conditions: pH, 8; $\mathrm{A}_{\mathrm{d}}, 1 \mathrm{~g}$ $\mathrm{L}^{-1}$; contact time, $180 \mathrm{~min}$; temperature, room temperature $\left(25 \pm 2^{\circ} \mathrm{C}\right)$.

The application of the adsorbent material in simulated effluent provides important information regarding the efficiency of this adsorbent in competitive effluents (Wamba et al. 2019). The WASC impressively adsorbed $98.57 \%$ and $88.08 \%$ of NM in the hospital effluent A and B, respectively. Using activated carbon from cocoa shell, Saucier (Saucier et al. 2015) reported efficiency of $95.58 \%$ in the removal of NM from simulated hospital effluent using an adsorbent dosage of $2.5 \mathrm{~g} \mathrm{~L}^{-1}$. This result indicates that WASC was a great and sustainable option for the utilization of WTS as an adsorbent for NM removal from hospital wastewater. 
Fig. 5 shows the continuous adsorption of NM by WASC. The influence of bed height and length was analyzed in two beds with different diameters and fixed adsorbent mass and flow rate.

Fig. 5. Fixed-bed adsorption of NM onto WASC. Conditions: $\mathrm{C}_{\mathrm{i}}, 200 \mathrm{mg} \mathrm{L}^{-1}$; $\mathrm{pH}, 8$; WASC mass, $1 \mathrm{~g}$; temperature, room temperature $\left(25 \pm 2^{\circ} \mathrm{C}\right)$; flow rate, $10 \mathrm{ml} \mathrm{min}^{-1}$.

Fig. 5 showed that the small internal diameters and, consequently, higher bed height provide better conditions from the NM adsorption by the WASC. This is related to the interaction time between NMWASC in the column. The $52 \mathrm{~mm}$ bed height provides a longer interaction time than the $28 \mathrm{~mm}$ height. Such occurrence is in agreement with the kinetic curves presented in Fig. 2, where it was observed that the adsorption of NM does not occur in an instantaneous way, such behavior in fixed-bed confirms that the adsorption of NM is mainly controlled by chemisorption (Patel 2020). This means that greater bed heights will allow for better performance because the unused fraction of WASC is reduced. WASC saturation time was longer for column 1 than for column 2, this is also related to the greater use of the adsorbent bed and consequently greater adsorption capacity.

To describe the dynamic behavior of the column, the Thomas and Yoon-Nelson models (Equations 11 and 12) were fitted to the experimental data. Table 6 summarizes the parameters found for each model and the respective error parameters $\left(R^{2}, X^{2}\right.$ and $\left.A R E\right)$.

Table 6 Model parameters of the fixed-bed NM adsorption onto WASC

Thomas and Yoon-Nelson models showed a good fit for both columns with high values for $R^{2}$. Column 1 presents higher values from $R^{2}$ and lower values from $X^{2}$ and ARE in comparison with Column 2. The explanation for this is that the adjustments can better predict the fixed bed curve when the adsorbent is saturated by NM molecules (Dotto and McKay 2020). The saturation of $1 \mathrm{~g}$ of WASC occurs for column 1 obtaining $q_{\max }$ of $217.28 \mathrm{mg} \mathrm{g}^{-1}$.

Fig. 6 shows the intensity of the molecular groups present in WASC before and after the NM adsorption.

Fig. 6. FT-IR spectra for WASC before and after the NM adsorption

After the adsorption, WASC demonstrates a decrease in alcoholic and phenolic O-H groups (a) compared to before the NM adsorption, it is represented by the intense band between $3600-3400 \mathrm{~cm}^{-1}$ (Calvete et al. 2010a, b; da Silva et al. 2011). The band range at $1700-1400 \mathrm{~cm}^{-1}$ indicates the presence of $\mathrm{C}=\mathrm{O}$ carboxylic acid stretching in WASC (b), the interference can be related to NH bend of NM (Caputo et al. 2012; Saucier et al. 2015). The 940-665 $\mathrm{cm}^{-1}$ band in WASC before the adsorption, indicates the presence of bending O-H (c) (Puchana-Rosero et al. 2016). The decrease in the O-H groups may be related to the disruption of these groups due to the interaction with NM molecules through $\mathrm{H}$ bonding (Saucier et al. 2015; Jauris et al. 2017). 
Based on the results of this work, it is possible to infer that the NM-WASC interaction is mainly controlled by intraparticle diffusion and chemisorption, but also presents attraction forces of $\mathrm{H}$ bonding. This great interaction of adsorbent-adsorbate might have positively influenced the high values obtained from $q_{\max }$ of isotherm studies and fixed-bed adsorption.

\section{Conclusion}

The WASC showed excellent results for the removal of NM anti-inflammatory. FD was successful in predicting the optimal $\mathrm{pH} 8$ and $A_{d}$ values. The equilibration time was reached in 120 min and the models that better described the kinetics data were the Intraparticle diffusion and Elovich model. The maximum amount adsorbed $\left(q_{\max }\right)$ of NM in batch tests was $274.99 \mathrm{mg} \mathrm{g}^{-1}$ and the isotherm data were better described by the Langmuir model. WASC proved to be efficient in the treatment of hospital wastewater, obtaining an impressive adsorption efficiency of $98.57 \%$ in a competitive environment with sugars, salts, and other inorganics. Finally, WASC was used in a fixed-bed for adsorption of NM in a continuous system, obtaining $q_{\max }$ values of $217.28 \mathrm{mg} \mathrm{g}^{-1}$, saturating in $250 \mathrm{~min}$ at a flow rate of $10 \mathrm{~mL} \mathrm{~min}^{-1}$. The results obtained in this work prove that WASC is an extremely promising adsorbent in the treatment of real pharmaceutical effluents.

\section{Data availability}

Not applicable.

\section{Consent for publication}

Not applicable.

\section{Availability of data and materials}

All data generated or analyzed during this study are included in this published article and its supplementary information files.

\section{Competing interests}

The authors declare that they have no competing interests.

\section{Funding}

Not applicable

\section{Acknowledgements}

The authors would like to thank the Federal University of Pampa (UNIPAMPA) for having made available its laboratory structure to carry out this work.

\section{Ethics approval and consent to participate}

Not applicable.

\section{Authors contributions}

Alaor Valério Filho: Conceptualization, methodology, investigation, formal analysis, visualization, and writing Luana Vaz Tholozan: Writing and editing Aline Lemos Arim: Investigation and paper review André R. F. de Almeida: Formal analysis, methodology, and paper review Gabriela S. da Rosa: Conceptualization, methodology, investigation, and writing of the review and editing. 
References

Ahmed MJ (2017) Adsorption of non-steroidal anti-inflammatory drugs from aqueous solution using activated carbons: Review. J Environ Manage 190:274-282. https://doi.org/10.1016/j.jenvman.2016.12.073

Al-Rashdi B, Tizaoui C, Hilal N (2012) Copper removal from aqueous solutions using nano-scale diboron trioxide/titanium dioxide (B2O3/TiO2) adsorbent. Chem Eng J 183:294-302. https://doi.org/10.1016/j.cej.2011.12.082

Alves CCO, Franca AS, Oliveira LS (2013) Removal of phenylalanine from aqueous solutions with thermo-chemically modified corn cobs as adsorbents. LWT - Food Sci Technol 51:1-8. https://doi.org/10.1016/j.1wt.2012.11.012

Arim AL, Quina MJ, Gando-Ferreira LM (2019) Uptake of trivalent chromium from aqueous solutions by xanthate pine bark: Characterization, batch and column studies. Process Saf Environ Prot 121:374386. https://doi.org/10.1016/j.psep.2018.11.001

Arim AL, Quina MJ, Gando-Ferreira LM (2018) Insights into the Sorption Mechanisms of Cr(III) by Chemically Modified Pine Bark. Chem Eng Technol 41:1378-1389. https://doi.org/10.1002/ceat.201800034

Braschi I, Blasioli S, Gigli L, et al (2010) Removal of sulfonamide antibiotics from water: Evidence of adsorption into an organophilic zeolite Y by its structural modifications. J Hazard Mater 178:218225. https://doi.org/10.1016/j.jhazmat.2010.01.066

Calvete T, Lima EC, Cardoso NF, et al (2010a) Application of carbon adsorbents prepared from Brazilian-pine fruit shell for the removal of reactive orange 16 from aqueous solution: Kinetic, equilibrium, and thermodynamic studies. J Environ Manage 91:1695-1706. https://doi.org/10.1016/j.jenvman.2010.03.013

Calvete T, Lima EC, Cardoso NF, et al (2010b) Removal of brilliant green dye from aqueous solutions using home made activated carbons. Clean - Soil, Air, Water 38:521-532. https://doi.org/10.1002/clen.201000027

Caputo G, Scognamiglio M, De Marco I (2012) Nimesulide adsorbed on silica aerogel using supercritical carbon dioxide. Chem Eng Res Des 90:1082-1089. https://doi.org/10.1016/j.cherd.2011.11.011

da Rosa GS, Vanga SK, Gariepy Y, Raghavan V (2019) Comparison of microwave, ultrasonic and conventional techniques for extraction of bioactive compounds from olive leaves (Olea europaea L.). Innov Food Sci Emerg Technol 58:102234. https://doi.org/10.1016/j.ifset.2019.102234 solutions by a chemically modified sugarcane bagasse lignin. Chem Eng J 168:620-628. https://doi.org/10.1016/j.cej.2011.01.040 
Dassanayake KB, Jayasinghe GY, Surapaneni A, Hetherington C (2015) A review on alum sludge reuse with special reference to agricultural applications and future challenges. Waste Manag 38:321-335. https://doi.org/10.1016/j.wasman.2014.11.025

Dotto GL, McKay G (2020) Current scenario and challenges in adsorption for water treatment. J Environ Chem Eng 8:103988. https://doi.org/10.1016/j.jece.2020.103988

Gonçalves AA, Araújo AF, De Mesquita JP, et al (2016) Characterisation of silica-supported Fe-Ni bimetallic nanoparticles and kinetic study of reductive degradation of the drug nimesulide. J Environ Chem Eng 4:4354-4365. https://doi.org/10.1016/j.jece.2016.09.038

Hidalgo AM, Murcia MD, Gómez M, et al (2017) Possible Uses for Sludge from Drinking Water Treatment Plants. J Environ Eng (United States) 143:1-7. https://doi.org/10.1061/(ASCE)EE.19437870.0001176

Jauris IM, Matos CF, Zarbin AJG, et al (2017) Adsorption of anti-inflammatory nimesulide by graphene materials: A combined theoretical and experimental study. Phys Chem Chem Phys 19:2209922110. https://doi.org/10.1039/c7cp04272h

Lima AB, Chaves SC, Silva LM da, et al (2013) Determinação de nimesulida por análise por injeção em fluxo com detecção amperométrica de múltiplos pulsos. Quim Nova 36:1296-1302. https://doi.org/10.1590/S0100-40422013000900004

Miao MS, Liu Q, Shu L, et al (2016) Removal of cephalexin from effluent by activated carbon prepared from alligator weed: Kinetics, isotherms, and thermodynamic analyses. Process Saf. Environ. Prot. 104:481-489

Papageorgiou M, Kosma C, Lambropoulou D (2016) Seasonal occurrence, removal, mass loading and environmental risk assessment of 55 pharmaceuticals and personal care products in a municipal wastewater treatment plant in Central Greece. Sci Total Environ 543:547-569. https://doi.org/10.1016/j.scitotenv.2015.11.047

Patel H (2020) Batch and continuous fixed bed adsorption of heavy metals removal using activated charcoal from neem (Azadirachta indica) leaf powder. Sci Rep 10:1-12. https://doi.org/10.1038/s41598-020-72583-6

Pauletto PS, Lütke SF, Dotto GL, Salau NPG (2020) Forecasting the multicomponent adsorption of nimesulide and paracetamol through artificial neural network. Chem Eng J 127527. https://doi.org/10.1016/j.cej.2020.127527

Peña-Guzmán C, Ulloa-Sánchez S, Mora K, et al (2019) Emerging pollutants in the urban water cycle in Latin America: A review of the current literature. J Environ Manage 237:408-423. https://doi.org/10.1016/j.jenvman.2019.02.100

Petrie B, Barden R, Kasprzyk-Hordern B (2015) A review on emerging contaminants in wastewaters and the environment: Current knowledge, understudied areas and recommendations for future 
monitoring. Water Res 72:3-27. https://doi.org/10.1016/j.watres.2014.08.053

Politano A, Argurio P, Di Profio G, et al (2017) Photothermal Membrane Distillation for Seawater Desalination. Adv Mater 29:1-6. https://doi.org/10.1002/adma.201603504

Puchana-Rosero MJ, Adebayo MA, Lima EC, et al (2016) Microwave-assisted activated carbon obtained from the sludge of tannery-treatment effluent plant for removal of leather dyes. Colloids Surfaces A Physicochem. Eng. Asp. 504:105-115

Reis GS dos, Bin Mahbub MK, Wilhelm M, et al (2016) Activated carbon from sewage sludge for removal of sodium diclofenac and nimesulide from aqueous solutions. Korean J Chem Eng 33:3149-3161. https://doi.org/10.1007/s11814-016-0194-3

Ribeiro PB, de Freitas VO, Machry K, et al (2019) Evaluation of the potential of coal fly ash produced by gasification as hexavalent chromium adsorbent. Environ Sci Pollut Res 26:28603-28613. https://doi.org/10.1007/s11356-018-3852-7

Rovani S, Rodrigues AG, Medeiros LF, et al (2016) Synthesis and characterisation of activated carbon from agroindustrial waste - Preliminary study of $17 \beta$-estradiol removal from aqueous solution. $\mathbf{J}$ Environ Chem Eng 4:2128-2137. https://doi.org/10.1016/j.jece.2016.03.030

Saucier C, Adebayo MA, Lima EC, et al (2015) Microwave-assisted activated carbon from cocoa shell as adsorbent for removal of sodium diclofenac and nimesulide from aqueous effluents. J Hazard Mater 289:18-27. https://doi.org/10.1016/j.jhazmat.2015.02.026

Seid-Mohammadi A, Asgarai G, Ghorbanian Z, Dargahi A (2020) The removal of cephalexin antibiotic in aqueous solutions by ultrasonic waves/hydrogen peroxide/nickel oxide nanoparticles (US/H2O2/NiO) hybrid process. Sep Sci Technol 55:1558-1568. https://doi.org/10.1080/01496395.2019.1603241

Silva EO da, dos Santos VD, de Araujo EB, et al (2020) Removal of methylene blue from aqueous solution by ryegrass straw. Int J Environ Sci Technol 17:3723-3740. https://doi.org/10.1007/s13762-020-02718-9

Simões dos Reis G, Sampaio CH, Lima EC, Wilhelm M (2016) Preparation of novel adsorbents based on combinations of polysiloxanes and sewage sludge to remove pharmaceuticals from aqueous solutions. Colloids Surfaces A Physicochem Eng Asp 497:304-315. https://doi.org/10.1016/j.colsurfa.2016.03.021

Singh A, Singh P, Kapoor VK (2001) Nimesulide. Anal Profiles Drug Subst Excipients 28:197-249. https://doi.org/10.1016/S1075-6280(01)28006-9

Siswoyo E, Qoniah I, Lestari P, et al (2019) Development of a floating adsorbent for cadmium derived from modified drinking water treatment plant sludge. Environ Technol Innov 14:100312. https://doi.org/10.1016/j.eti.2019.01.006

Sophia A. C, Lima EC (2018) Removal of emerging contaminants from the environment by adsorption. 
Streit AFM, Collazzo GC, Druzian SP, et al (2020) Adsorption of ibuprofen, ketoprofen, and paracetamol onto activated carbon prepared from effluent treatment plant sludge of the beverage industry. Chemosphere. https://doi.org/10.1016/j.chemosphere.2020.128322

Valério Filho A, Kulman RX, Janner NN, et al Optimization of cationic dye removal using a high surface area-activated carbon from water treatment sludge. Bull Mater Sci. https://doi.org/10.1007/s12034020-02333-X

Valério Filho A, Xavaré Kulman R, Tholozan LV, et al (2020) Preparation and Characterization of Activated Carbon Obtained from Water Treatment Plant Sludge for Removal of Cationic Dye from Wastewater. Processes 8:1549. https://doi.org/10.3390/pr8121549

Wamba AGN, Ndi SK, Lima EC, et al (2019) Preparation, characterization of titanate nanosheetpozzolan nanocomposite and its use as an adsorbent for removal of diclofenac from simulated hospital effluents. J Taiwan Inst Chem Eng 102:321-329. https://doi.org/10.1016/j.jtice.2019.05.001

Wang Z, Nengzi L chao, Zhang X, et al (2020) Novel NiCo2S4/CS membranes as efficient catalysts for activating persulfate and its high activity for degradation of nimesulide. Chem Eng J 381:122517. https://doi.org/10.1016/j.cej.2019.122517

Xu G, Yang X, Spinosa L (2015) Development of sludge-based adsorbents: Preparation, characterization, utilization and its feasibility assessment. J Environ Manage 151:221-232. https://doi.org/10.1016/j.jenvman.2014.08.001 
Figures

a b
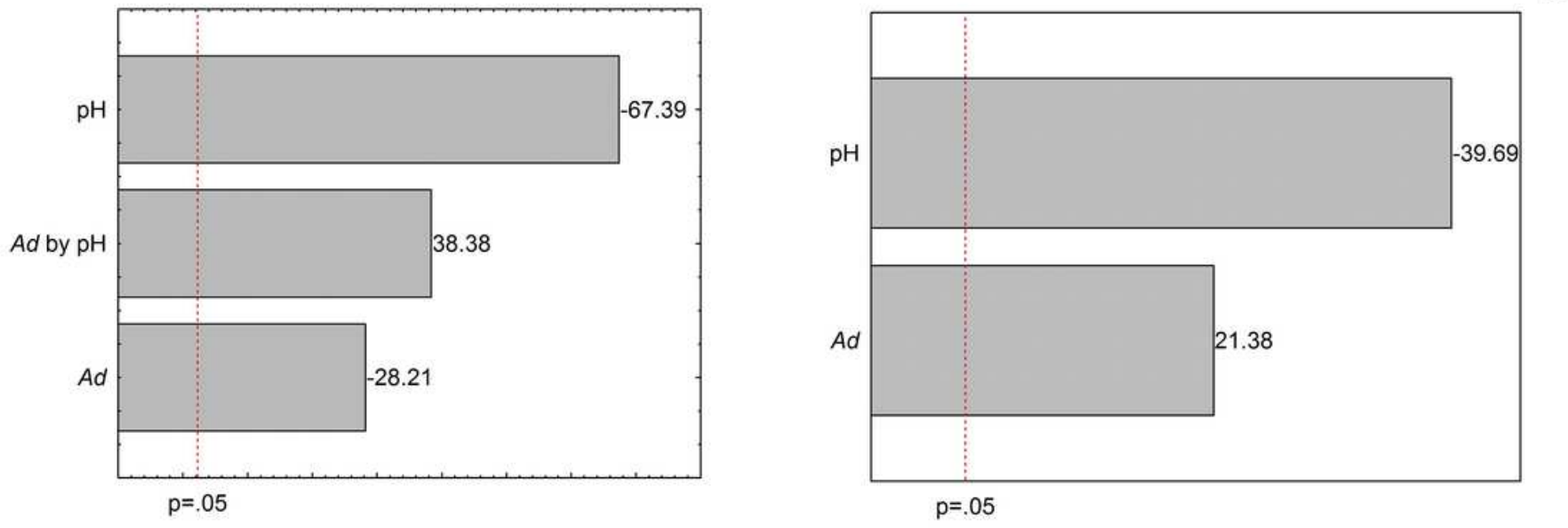

Figure 1

Pareto charts of the estimated effects on adsorption capacity (a) and efficiency (b)
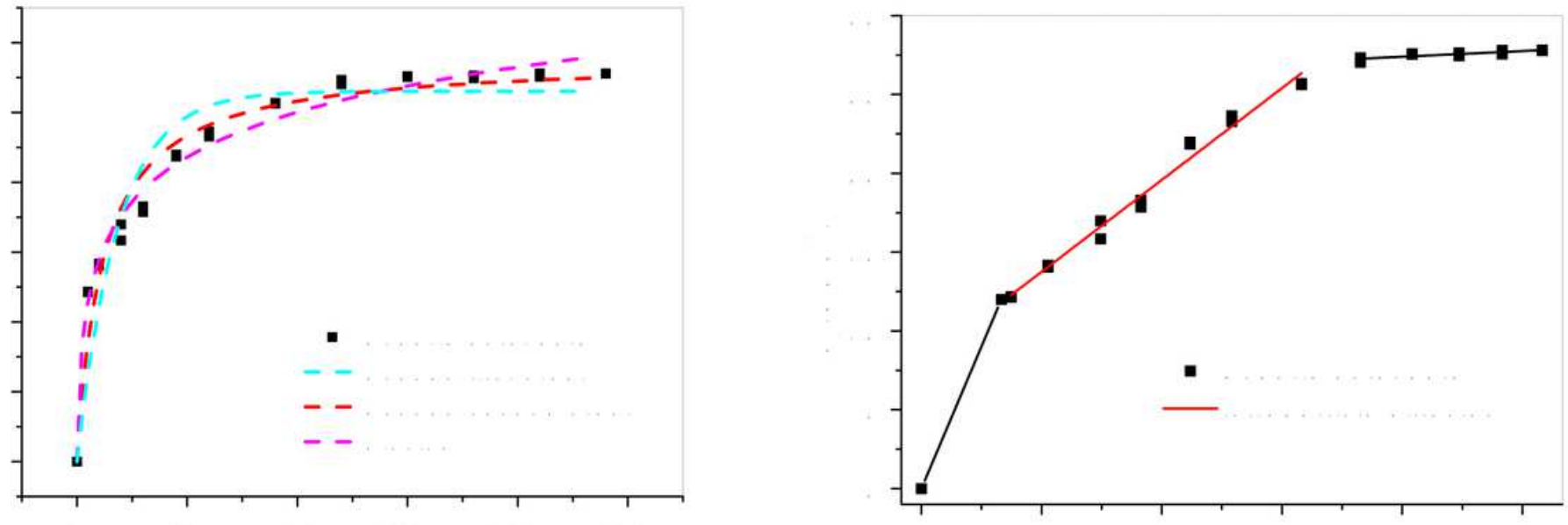

Figure 2

Please see the Manuscript PDF file for the complete figure caption 


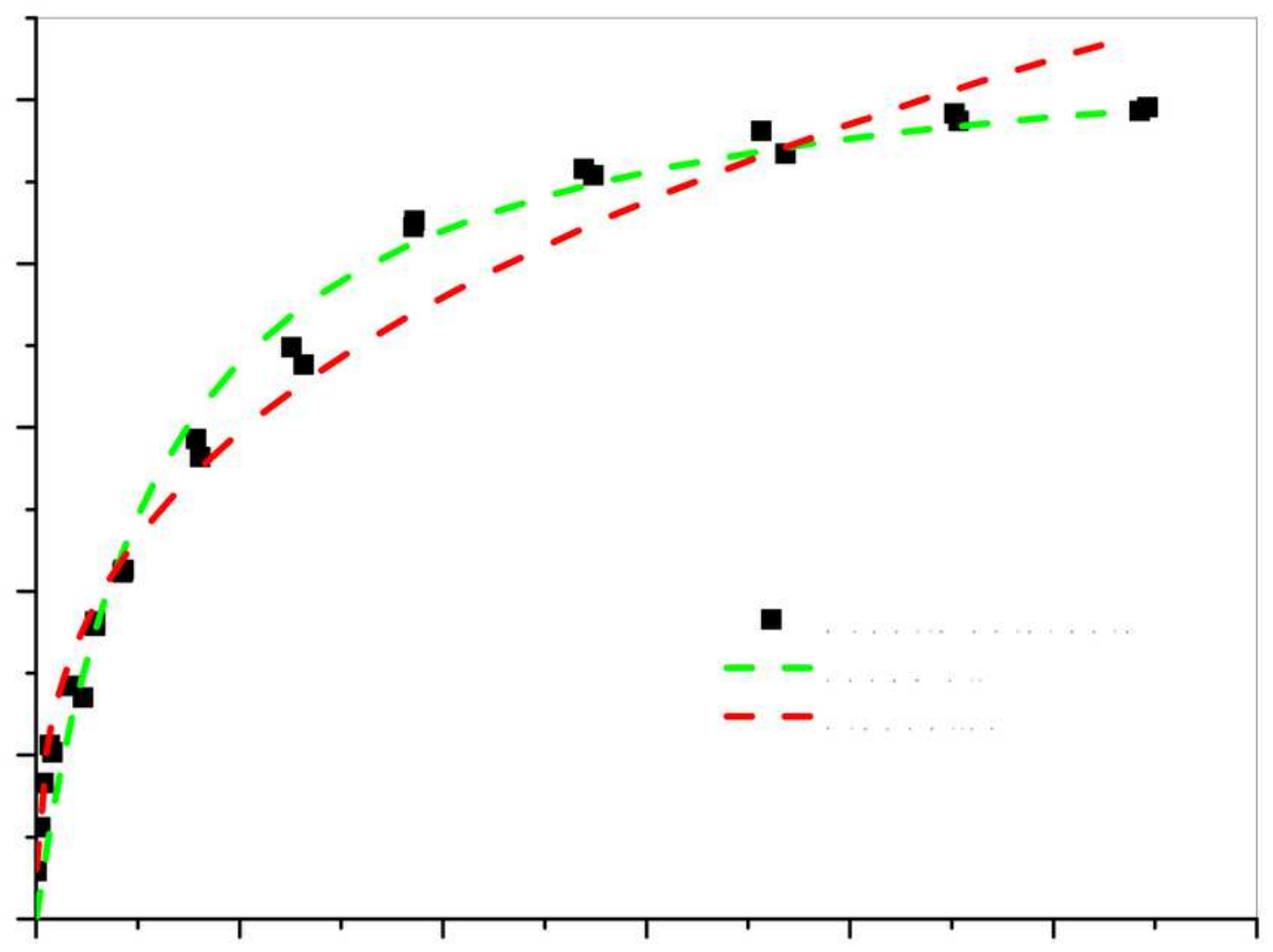

Figure 3

Please see the Manuscript PDF file for the complete figure caption 


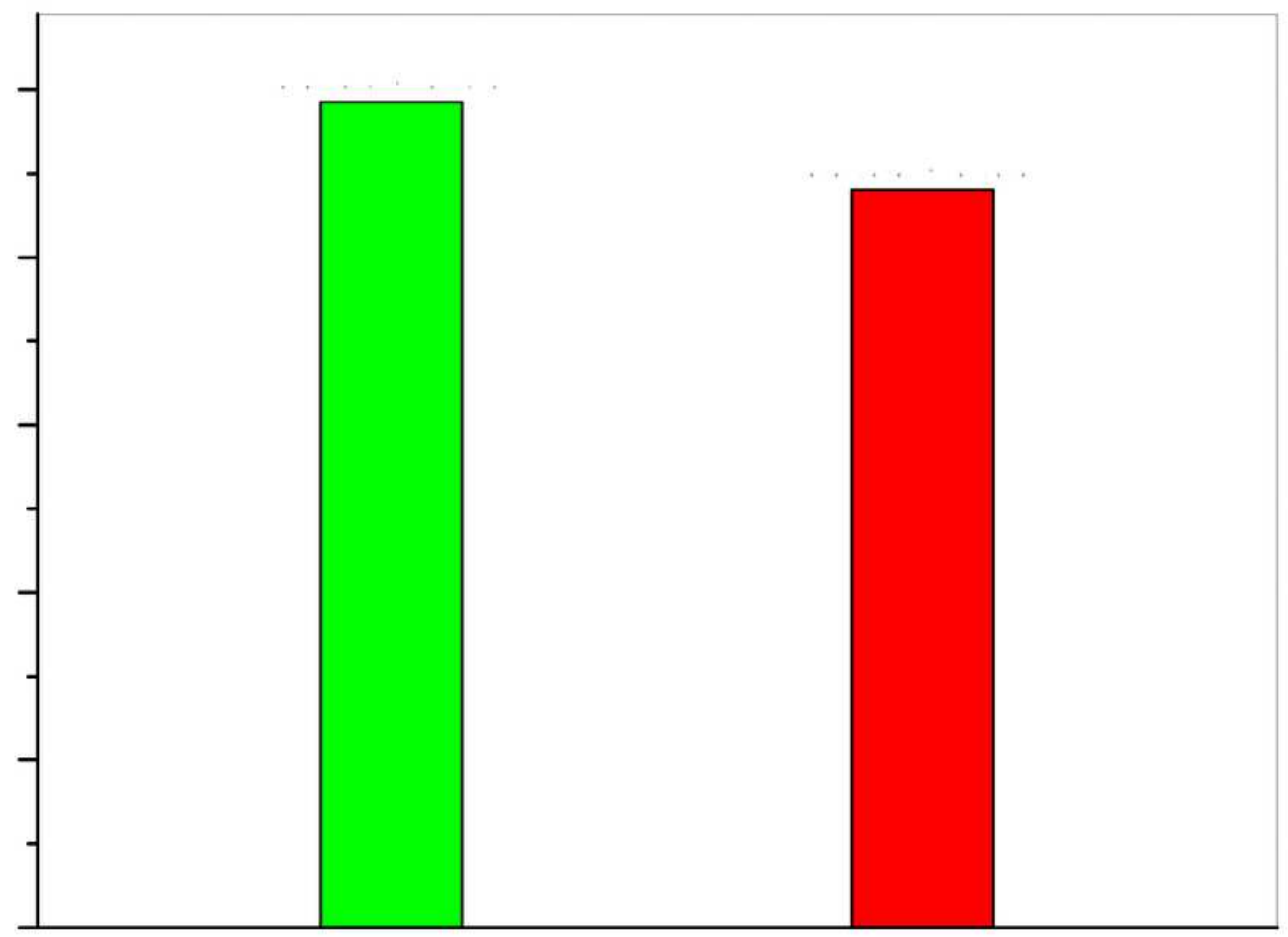

Figure 4

Please see the Manuscript PDF file for the complete figure caption 


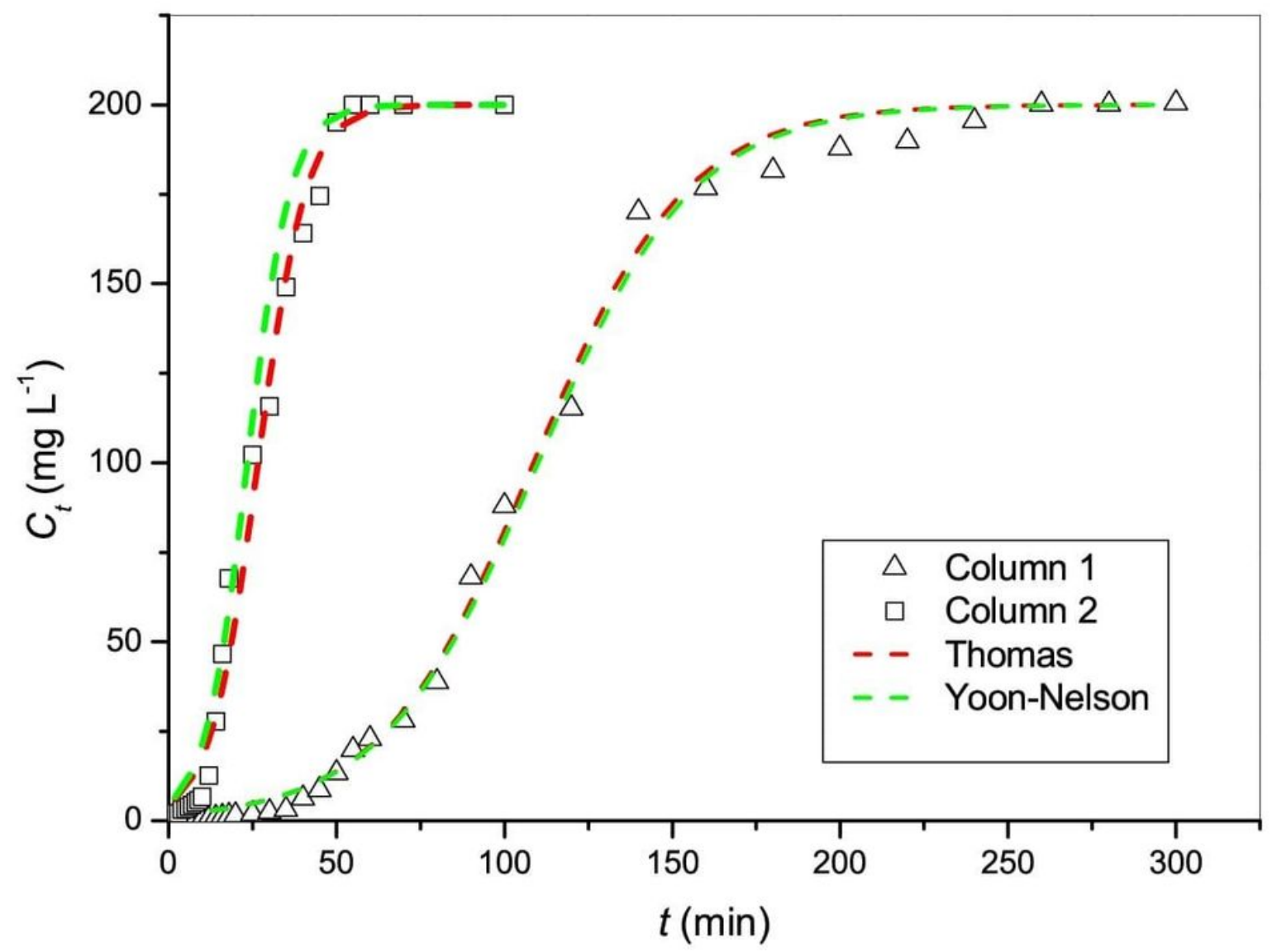

Figure 5

Please see the Manuscript PDF file for the complete figure caption 


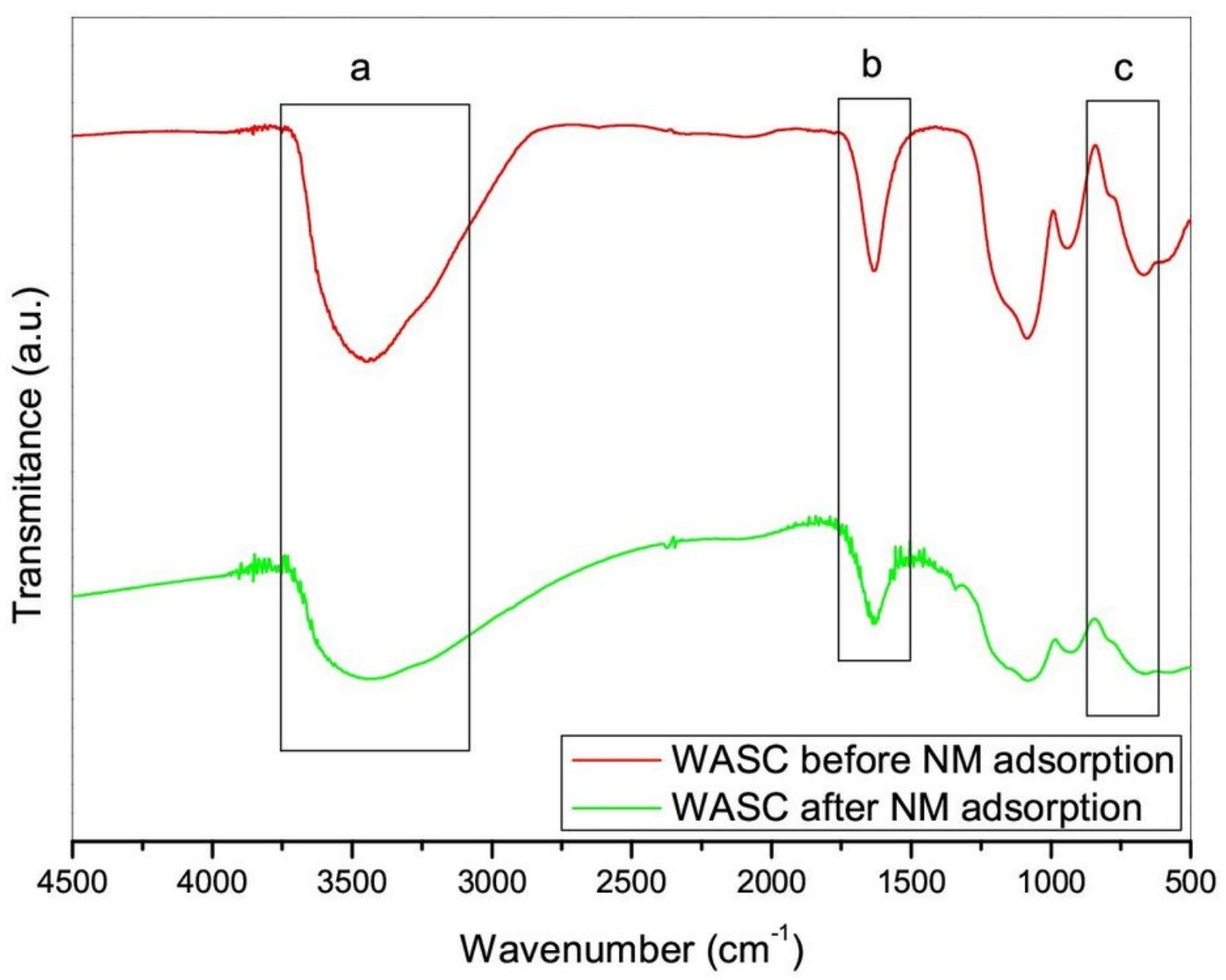

Figure 6

FT-IR spectra for WASC before and after the NM adsorption

\section{Supplementary Files}

This is a list of supplementary files associated with this preprint. Click to download.

- Table1.docx

- Table2.docx

- Table3.docx

- Table4.docx

- Table5.docx

- Table6.docx 